\title{
LA REPRESENTACIÓN DEL POPORO EN EL TEJIDO DE LA MOCHILA RITUAL IKA
}

\author{
THE REPRESENTATION OF THE POPORO IN THE TISSUE OF \\ THE IKA RITUAL BACKPACK \\ A REPRESENTAÇÃO DO POPORO NO TECIDO DA MOCHILA \\ RITUAL IKA
}

Por:

Gonzalo Ramírez G. ${ }^{1}$

Profesor

Universidad de Santander (UDES)

gonzaramirezg@yahoo.com

Horacio Rosales C. ${ }^{2}$

Profesor

Universidad Industrial de Santander (UIS)

horocue@yahoo.com

Resumen: El presente trabajo hace parte de una investigación semiótica sobre los objetos utilizados en la práctica cultural conocida como "poporeo", o consumo ritual de la hoja de coca, en la comunidad indígena Ika que habita actualmente la vertiente meridional de la Sierra Nevada de Santa Marta (Colombia). El propósito del estudio es conocer las operaciones de construcción de sentido que se generan en la práctica ritual de este, específicamente alrededor del poporo tejido en la mochila ika.

Palabras Clave: Semiótica, Comunicación, Ritual, Coca, Poporo, Ika.

Abstract: This work is part of a semiotic research on the objects used in a cultural practice known as "poporo" or ritual of consumption of the coca leaf by Ika, an indigenous community that dwells in the southern slope of the Sierra Nevada of Santa Marta (Colombia). The purpose of the study is to understand the meaning-building operations that take place during the practice of the ritual, specifically those that are related to the poporo tissue of the Ika backpack.

Keywords: Semiotics, Communication, Ritual, Coca, Poporo, Ika. 
Resumo: O presente trabalho faz parte da pesquisa semiótica sobre os objetos usados na prática cultural conhecida como "poporeo", ou consumo ritual da folha de coca, na comunidade indígena Ika, que mora na região meridional da Sierra Nevada de Santa Marta (Colômbia). O propósito do estudo é conhecer as operações de construção do sentido que se geram nesta prática ritual, especificamente ao redor do poropo tecido na mochila Ika.

Palavras-chave: Semiótica, Comunicação, Ritual, Coca, Poporo, Ika.

\section{Introducción}

Esta investigación se centra en el estudio de la práctica del ritual del consumo de la hoja de coca, específicamente en la mochila Ika y el poporo representado en ella. El análisis centrado en la imagen plasmada en el tejido no se aparta de elementos fundamentales para el análisis de prácticas semióticas, como la consideración de la organización socioculturalmente situada del fenómeno y las dimensiones semionarrativa, pasional y axiológica que determinan tanto el diseño (configuración del tejido y sus imágenes) como el uso ritual de los objetos. Para el análisis se recurre a las herramientas de la semiótica visual y los recursos metodológicos de la Escuela de París.

El análisis semiótico de los objetos rituales de la cultura ika tiene un valor sociocultural que radica en analizar, para valorar, aspectos de una forma de vida ancestral colombiana en tensión con la cultura occidental. El estudio de las prácticas culturales de la cultura Ika y de las relaciones de ésta con el entorno natural, los fenómenos de contacto y la lucha por la preservación de elementos identitarios de la comunidad no solo configura un complejo universo de significación, sino que abre horizontes de comprensión de la diversidad de formas de vida que hacen parte de las complejas dinámicas, muchas veces ignoradas y marginadas, de una cultura colombiana que se autodenomina multicultural e incluyente.

\section{El ritual y el poporeo}

El ritual es una práctica semiótica compleja, una serie de acciones significantes realizadas por su valor simbólico y efecto pragmático, reguladas por condicionamientos sociales y que derivan de una visión de mundo construida históricamente en la vida colectiva. Los ritos convalidan la estructura social y promueven la resolución de problemas personales y sociales al facilitar la manifestación de ideologías, valores, y normas, así como la estabilización del sentido común o del orden de las cosas “como deben ser". De este modo, el ritual es una serie de comportamientos repetitivos y estereotipados, que permiten regular el funcionamiento social y familiar, median la cultura y los valores entre los actores sociales contemporáneos y de diferentes generaciones. A partir de esto, puede afirmarse que el ritual es una práctica social que permite conservar la unión de los miembros de la comunidad por intermedio de un sistema de valores que, en un modo de existencia virtual, se actualizan en la realización del ritual para preservar la memoria y reafirmar, en las formas establecidas de ver el mundo, los asideros identitarios de los sujetos. 
Con fines alimenticios asociados a las creencias religiosas, "poporear" es un ritual ancestral y cotidiano que, en las culturas colombianas, consiste en la extracción y consumo de los alcaloides contenidos en la hoja de coca, para lo cual el ika utiliza al menos tres objetos que funcionan como contenedores de diferentes contenidos: el poporo contenedor de la cal, la mochila que contiene la hoja de coca, y el jwämisi que contiene extracto de tabaco. Para realizar esta práctica, el jefe ritual otorga el permiso de consumir la hoja de coca al joven varón ika; esta connivencia es el símbolo del paso de la infancia a la adultez. A partir del rito de paso, se considera al joven hombre como teti, como un miembro de la comunidad con responsabilidades y derechos. En palabras de Van Gennep (1986), aquí se configura un rito de paso o «transición» que se caracterizan por tres fases, a saber: la separación, el limen y la agregación, que son fases que determinan las competencias y definición identitaria del sujeto en el universo sociolectal.

\section{La mochila y el ritmo del tejido}

En el resto de Colombia, la mochila es el objeto más representativo de la cultura ika. Tradicionalmente, este objeto contenedor es tradicionalmente tejida por las mujeres indígenas o güatis para una persona en especial y con un propósito específico; dependiendo del tipo de tejido (cerrado del nudo y espacio entre los nudos del tejido) la mochila es usada como funda de protección para el poporo o para contener la hoja de coca que se va a consumir.
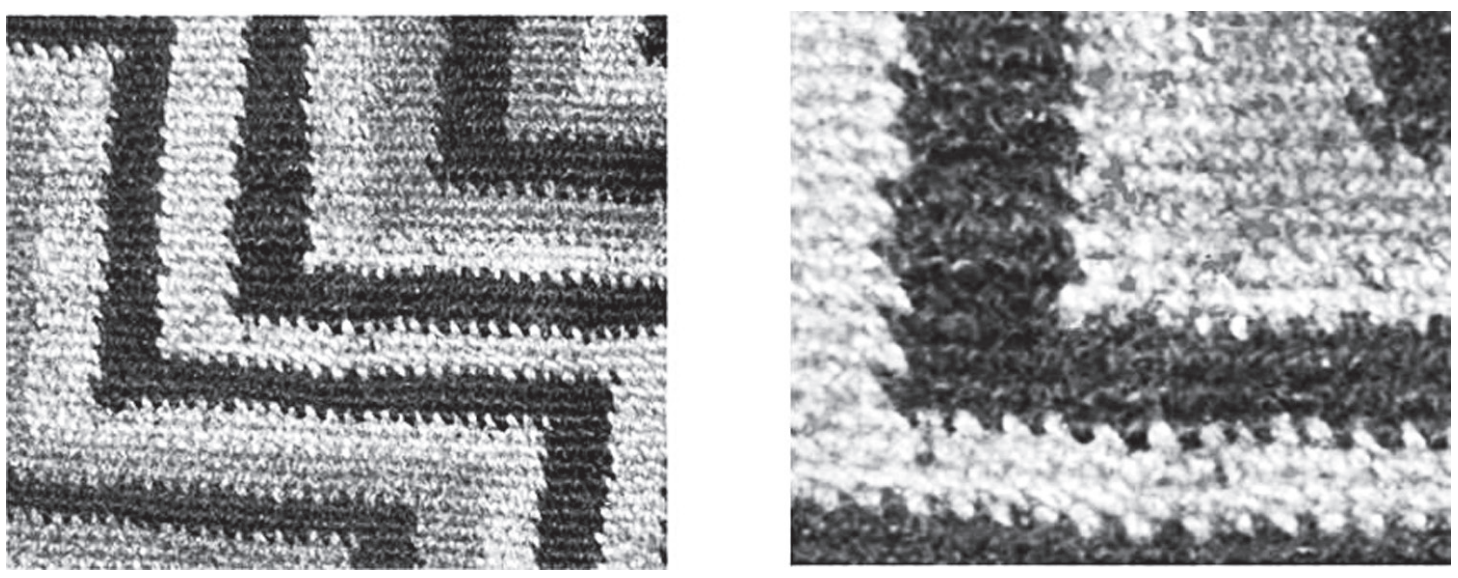

Figura 1. Dos tipos de trama en el tejido de la mochila ika.

Para describir el funcionamiento de los elementos plásticos presentes en la mochila, debe considerarse la textura, definida en este caso, como una microtopografía constituida por la repetición de elementos (Groupo $\mu$, 1993) que tiene efectos multimodales (táctiles y visuales). En la mochila, la textura que construye la imagen visual está formada por las características propias del tejido que son captadas por la vista y por el tacto: el nudo, el ritmo o tonicidad que produce el entrecruzamiento de 
los hilos cada intervalo, la repetición. El ritmo, siguiendo a Claude Zilbelberg (2001), vendría determinado por el efecto de combinación de la tonicidad y la temporalidad en que se produce la alternancia entre tónico/átono. En el caso del tejido, se trata de los intervalos en los que alternan espacialmente (o temporalmente, según el recorrido del ojo o del tacto sobre la superficie o en contacto con ella) la tensión del nudo y la lasitud de los hilos que se desprenden de un nudo y convergen en otro; este fenómeno es recurrente y lo apretado o estrecho del intervalo entre nudos causa una mayor o menor flexibilidad del tejido.

Al mismo tiempo, la textura está determinada, en la sensación visual, por pixeles coloreados que corresponden a la conformación de cada una de las puntadas del tejido; el conjunto de los pixeles visuales o de puntos de tejido correspondientes al mismo efecto cromático o mancha, dibujan zonas cromáticas diferenciables y que pueden contener flujos de información individual, analizables como elementos plásticos (plano de la expresión) que convergen en figuras que pueden ser asociadas a elementos del mundo natural, como la del poporo o una secuencia rítmica de figuras geométricas. Así, el color utilizado para cada una de las puntadas del tejido determina finalmente el dibujo texturizado que se está tejiendo, mientras que la forma de la puntada determina la funcionalidad o el uso final de la mochila. De esta forma, las características del pixel crean un flujo independiente de información global que permite la visualización total de la imagen inscrita en la mochila.

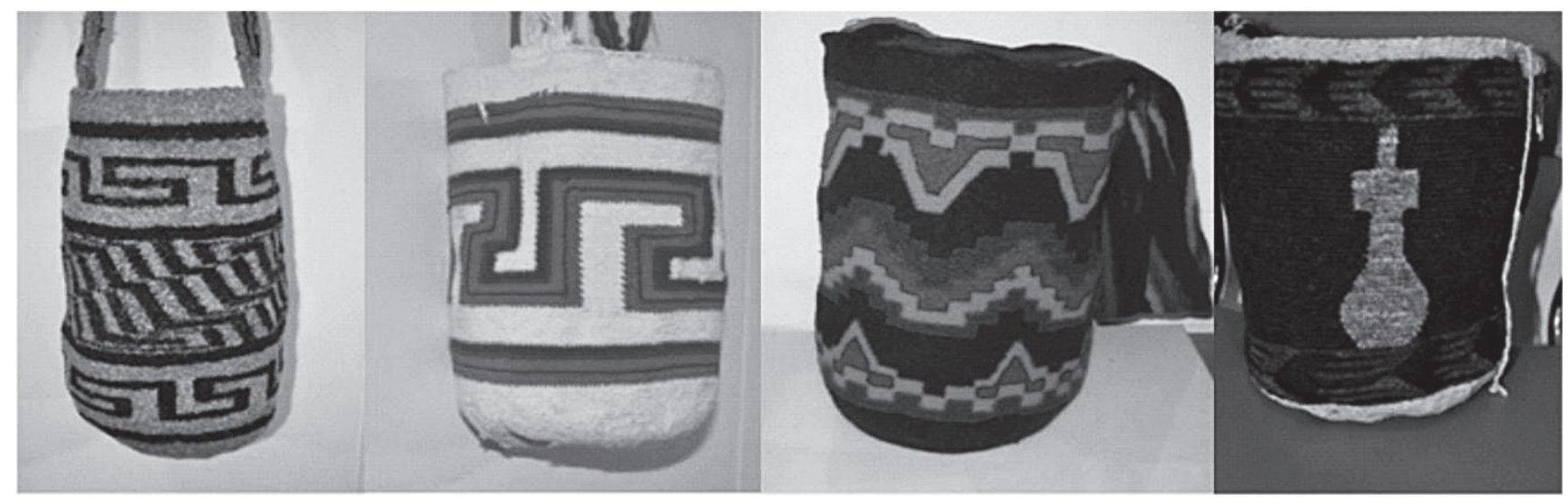

Figura 2. Efectos visuales y de textura del tejido (trama y figuras por efectos cromáticos).

Visualmente, el nudo del tejido determina la dimensión de la mácula ${ }^{3}$, de modo que un tejido muy fino tendrá máculas pequeñas y un tejido grueso células de color más grandes; es decir, al modificar la mácula se deforma y se transforma la imagen que de ella depende o de la cual ella hace parte constituyente. 
Es preciso señalar que dependiendo de las características del nudo, el uso o rol mediador de la mochila cambia con respecto del objeto que puede portar: una puntada de células pequeñas, tanto cromáticas como en el tejido, se utilizará para tejer una mochila ziju, de tamaño pequeño, y que funciona como contenedor para la hoja de coca; una puntada de células grandes se emplea para tejer una mochila joburumusi, de tamaño mediano y que funciona como contenedor para el poporo.

\section{La representación del poporo en la mochila tejida}

La imagen tejida en la mochila puede remitir a otro de los elementos usados en el ritual del consumo de la hoja de coca, como el poporo o recipiente contenedor elaborado a partir del fruto del totumo. El poporo se confecciona perforando el fruto por la parte superior para sustraer las semillas y luego se seca al sol; el recipiente se usa como contenedor de la cal, obtenida de conchas de mar, que el ika consume extrayendo por medio de una vara de madera llamada sokülum. La imagen del poporo en la superficie del tejido de la mochila que aquí se analiza puede ser segmentada en cuatro cuadrantes para identificar los elementos visuales contenidos en cada uno de ellos y que aclaran no sólo sobre la estructura de la imagen de la cosa representada, sino del poporo mismo.
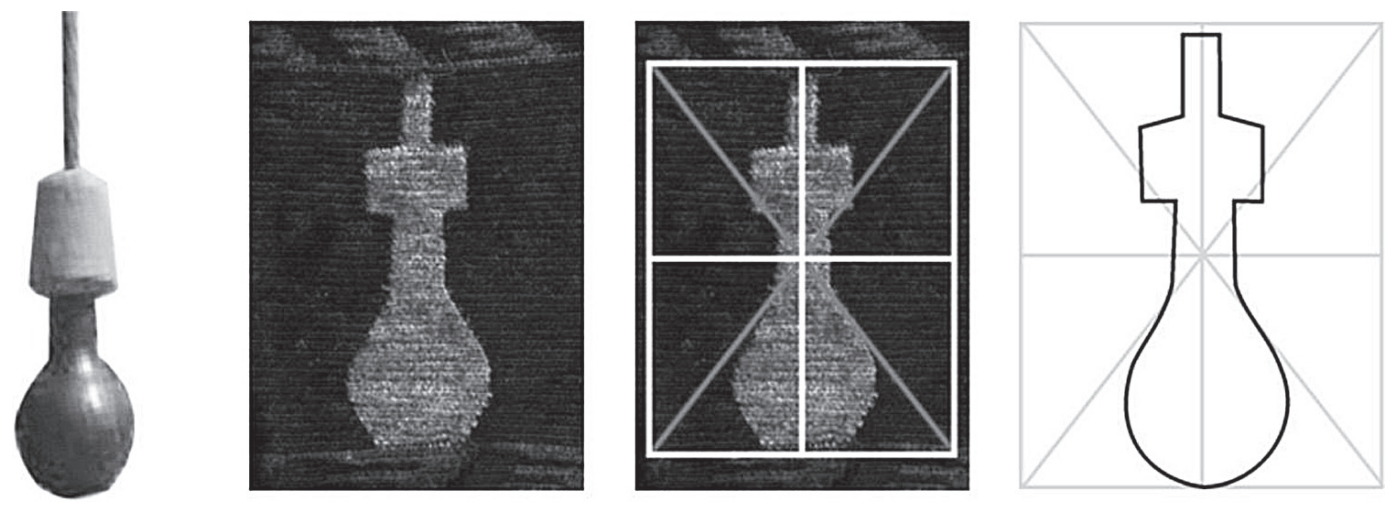

Figura 3. Segmentación en cuatro cuadrantes de la imagen del poporo en la mochila.

Esta descripción del objeto será incompleta si no se aborda con los textos aportados por los informantes de la investigación cualitativa en que se enmarca este análisis. Así, un informante miembro de la cultura Ika y practicante del poporeo, afirma que

El ika escribe en su poporo todo su pensamiento que se convierte en piedra y lo va concentrando en el enchape (mezcla de cal y saliva, con el sumo de coca con el tabaco) y eso va armando este material duro encima del calabazo, por eso dicen los mamos que el pensamiento de uno está metido ahí, ese es el pensamiento de uno que está grabado en piedra.

La distribución topológica muestra la importancia de /arriba/ en el lugar que semióticamente representa lo ideal, donde se ubica la costra de cal; en esta sección de 
la imagen está la representación del "enchape”, que para la cultura Ika representa la escritura del pensamiento, y la vara con la que se extrae la cal, el sokülum, posee una fuerte connotación masculina y que se inserta en el poporo de manera vertical. La parte inferior /abajo/ representa lo real y está asociado, según los datos aportados por los informantes, con la esposa o compañera, y en un sentido más amplio con la fertilidad y la naturaleza, la parte del cuerpo que porta la vida (vientre materno) y que queda soportada por la mano del hombre que carga y emplea el poporo. Este tipo de división nos permite asignar "el valor de lo real a la sección inferior y el valor de lo ideal a la sección superior" (Kress, et al., 2000, p.394) al mostrarse la imagen como simétrica respecto al eje vertical la distinción izquierda derecha no tiene relevancia. Las categorías asociadas y opuestas en pares (/arriba/ e /ideal/ vs/abajo/ y /terrenal/) parecieran tener un carácter axiológico cuyas variaciones están más asociadas, en el caso de las culturas de la Sierra Nevada de Santa Marta, a procesos identitarios de grupos, pues la forma inferior del poporo determina la etnia a la cual pertenece el portador: si el vientre del poporo es redondeado, es de procedencia ika, pero si la forma tiende a afilarse, el poporo pertenecerá a otra etnia.

Además de esta dimensión figurativa, y entrando en el plano del contenido, la representación del poporo tejido en la mochila ika corresponde a un mitograma. Jean-Marie Floch, citando a André Leroi-Gourhan, define el mitograma, por oposición al pictograma, no solo como un cierto tipo de imágenes, sino también como un cierto modo de pensamiento propiamente mítico (Floch, 1993, p.190) en tanto que el objeto contiene un sí un complejo semántico elaborado culturalmente, al punto que no solo es una figura de otra cosa ausente, sino de algo que tiene anclaje en el pasado, en el presente y una proyección hacia el futuro. En el caso de la imagen del poporo que ocupa gran parte de la zona frontal de la mochila, aparece sugerida una aspectualización temporal que involucra tres estados: a) un pasado visto como el estado inicial o previo a la acumulación calcárea en el cuello del poporo; b) un presente entendido en el estado actual del poporo en la imagen que lo representa, con la gruesa capa de cal (lo que alude a una acumulación de pensamientos del usuario, puesto que mientras se hacen las capas de cal, el ika reflexiona o procede en un estado de contemplación) y c) un futuro, en el que la formación calcárea, o “enchape”, estará terminada y dejará de crecer por la inactividad (fallecimiento) del usuario. Así, el pictograma puede presentarse como la alineación de las fases sucesivas de una acción, en la que se evoca el desarrollo, en el tiempo, de la vida del poporo y del usuario del mismo en el seno de una práctica ritual cotidiana.

El enunciatario que emplea la mochila o mira la imagen del poporo, traduce, por efecto cognitivo natural en la representación, una imagen en la presentificación (en ausencia o no) del objeto del mundo natural (poporo), para ello, el enunciador (típicamente una enunciadora, sea la mujer o la cultura) emplea de enunciación la estilización de las formas, lo que es "una operación retórica sobre la imagen e implica frecuentemente una geometrización de los trazados" (Groupe $\mu$, 1993, p.330).
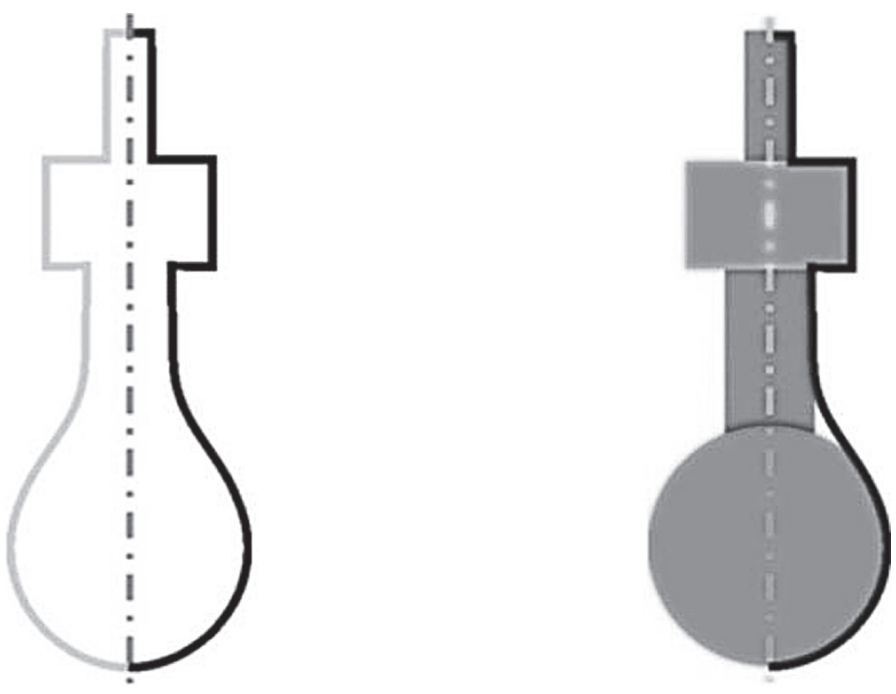

Figura 4. Reconocimiento de la simetría del poporo trazado en la mochila. 
Según los postulados de la Gestalt, que ha aportado valiosos estudios y experimentos al campo de la percepción, recogiendo datos, buscando la significancia de los patrones visuales y descubriendo como el organismo humano ve y organiza el input visual y articula el output visual (Dondis, 1998, p. 35), la figura hace referencia al objeto que estamos percibiendo y el fondo a los espacios en derredor del objeto. En este tipo de análisis, el campo perceptual puede dividirse en figura contra un fondo; la figura del poporo ocupa una posición central con respecto al fondo de la cara principal de la mochila; de esta manera, crea tensión entre su forma y el límite del fondo, que "tiende a rechazar toda forma que se destaca sobre el fondo y, por consiguiente, a centrarla" (Groupe $\mu$, 1993, p. 198) y, lo que es más importante, la simetría respecto al eje vertical y la posición central que permite que las fuerzas o tensiones se anulen, de modo que la forma de la imagen del poporo se configura como fuerte (único objeto representado, en posición central y dominante) y estable (simetría).
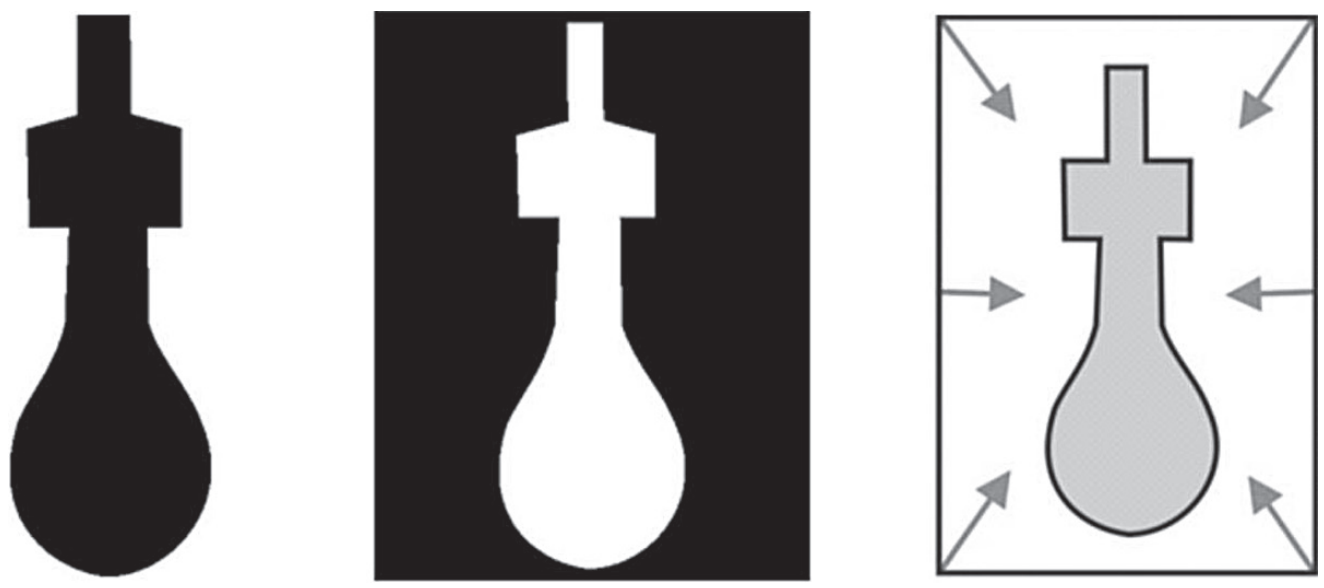

Figura 5. Oposición entre figura y fondo del poporo representado en la mochila ika.

\section{Conclusión}

El poporo ha recibido la huella del cuerpo del ika, que frota el sokülum sobre su superficie y construye el recubrimiento calcáreo que afecta las propiedades externas del objeto, su forma color y textura, pero a la vez permanecen las condiciones de funcionalidad como contenedor de una substancia (la cal) cuyo empleo en el consumo de la hoja de coca está ritualizado. Sin embargo, las propiedades internas del objeto no se modifican, permanecen en el tiempo. Con respecto del movimiento repetitivo del sokülum sobre la superficie del poporo, podrá afirmarse que se trata de una acción recurrente, rítmica, que acumula los elementos necesarios para formar la pátina en los procesos de contemplación que acompañan el consumo de la hoja de coca; es por ello que el poporo acumula las marcas que testimonian la presencia y la manipulación de su dueño y de la cultura ika. La pátina designa, así, toda alteración superficial y regular que el tiempo impone a los objetos constituidos de una materia dura estable y en general inmutable (Fontanille, 2004, p. 330). En este sentido, el poporo en la representación de la mochila es un objeto completo por cuanto posee su pátina (costra de cal), pero también podría ser una prótesis magnificante. 
Para Umberto Eco, una prótesis magnificante hace algo que “quizá hemos soñado hacer con nuestro cuerpo, sin conseguirlo jamás: como el telescopio, el microscopio, pero también jarras y botellas, cestos y sacos, el huso, y ciertamente el trineo y la rueda" (Eco, 1997, p.421). El poporo se comporta de un modo similar, no por ser un contenedor de la cal, sino como una materialización de lo abstracto: el tiempo, la vida del sujeto, el pensamiento del usuario, el cumplimiento del deber ser en el ámbito de la comunidad, etc. La forma misma del calabazo opera como una interfaz-sujeto que se ajusta a la mano del usuario y como una interfaz-objeto (el interior del poporo) que es adaptada como contenedor de la cal. Con el enchape o pátina, "el instrumento ha adoptado más que la forma del objeto o de la mano, la forma de los gestos que ha permitido llevarla cabo". (Fontanille, 2001, p. 344).

En el nivel axiológico, a propósito de la segmentación topológica con la oposición arriba/abajo, puede relacionarse con la categoría tímica euforia/disforia, siendo el poporo representado en el tejido y en su uso real, con su capucha de cal solidifica (arriba), un símbolo aceptado y valorado positivamente en el sentido común de la cultura ika. La práctica cultural del consumo de la hoja de coca permanece como un ritual que reconstruye en todo momento la identidad de la cultura ika y refuerza

la memoria que cohesiona su tejido social en tensión, naturalmente, con el llamado mundo moderno que asedia las dinámicas de la forma de vida de los ika.

\section{Notas}

1 Grupo de investigación CIMEP

${ }^{2}$ Miembro del grupo de investigación CUYNACO, Cultura y Narración en Colombia.

${ }^{3}$ Se entiende por mácula la discretización más o menos avanzada del elemento pictórico, cuando el elemento se inscribe solamente en dos dimensiones (Groupe $\mu$, 1993:187).

\section{Referencias}

Dondis, D. A., (1973 [1998]). A primer of visual literacy. (Tr. Esp. La sintaxis de la imagen, introducción al alfabeto visual). Barcelona: Gustavo Gili.

Eco, U., (1997 [1999]). Kant e l'ornitorinco. (Tr. Esp. Kant y el ornitorrinco). Barcelona: Lumen.

Floch, J., (1991 [1993]), Sémiotique, marketing et communication. Sous les signes, les stratégies. (Tr. Esp. Semiótica marketing y comunicación. Bajo los signos, las estrategias). Barcelona: Paidós.

Fontanille, J., (1998 [2001]). Sémiotique du discours. (Tr. Esp. Semiótica del Discurso). Lima: Universidad de Lima.

Fontanille, J., (2004 [2008]). Some et séma: Figuraes du corps. (Tr. Esp. Soma y sema. Figuras semióticas del cuerpo). Lima: Universidad de Lima.

Gennep, A.V. (1986). Los ritos de paso. España: Taurus

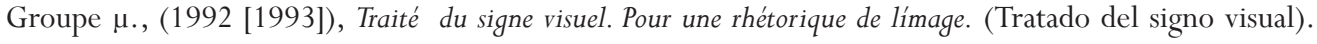
Madrid: Cátedra.

Kress, G., Leite-García, R. y Van Leeuwen, T., (2000). Semiótica discursiva. En Van Dijk, T. (comp.), El discurso como interacción social. 373-416. Barcelona: Gedisa.

Zilbelberg, Claude. Remarques sur l'assiettesémiotique du rytme. Recuperado en http://www. claudezilberberg.net/ download/downset.htm,13 mar. 2011. 